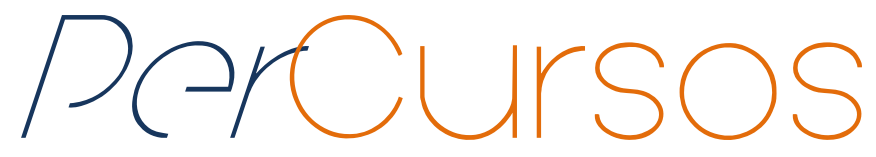

\title{
Educação do Campo no ensino superior: o caso da Universidade Federal da Fronteira Sul - Campus Laranjeiras do Sul
}

\section{Resumo}

Este trabalho apresenta algumas experiências do curso Interdisciplinar em Educação do Campo: Ciências Sociais e Humanas - Licenciatura, da Universidade Federal da Fronteira Sul - Campus Laranjeiras do Sul, Paraná. O curso é resultado das políticas públicas de ampliação e interiorização do ensino superior público no Brasil, no início do século XXI. A pesquisa foi realizada por meio de revisão teórica e estudo dos marcos normativos da Educação do Campo no Brasil, realização de entrevistas com os(as) estudantes, observação participante e consulta aos dados de registros dos acadêmicos, disponibilizados pela secretaria do curso e pela Assessoria de Assuntos Estudantis. O resultado revela o acesso, a permanência e a conclusão do ensino superior a um público que, historicamente, teve o seu direito à educação negado no Brasil, como os indígenas e os camponeses. Constataram-se, também, os novos conhecimentos agregados, os aprendizados revelados pelos(as) estudantes e a importância da pedagogia da alternância para a conclusão do curso.

Palavras-chave: Educação do Campo. Pedagogia da alternância. Direito à educação.

\section{Maria Eloá Gehlen}

Doutora em Educação pela

Universidade Federal do Rio

Grande do Sul - UFRGS.

Professora da Universidade

Federal da Fronteira Sul - UFFS -

Campus Laranjeiras do Sul.

$$
\text { Brasil }
$$

maria.gehlen@uffs.edu.br

\section{Roberto Antônio Finatto}

Doutor em Geografia pela Universidade Federal de Santa Catarina - UFSC. Professor da Univ. Federal da Fronteira Sul UFFS - Campus Laranjeiras do Sul. Brasil robertofinatto@gmail.com

\section{Para citar este artigo:}

GEHLEN, Maria Eloá; FINATTO, Roberto Antônio. Educação do Campo no ensino superior: o caso da Universidade Federal da Fronteira Sul - Campus Laranjeiras do Sul. Revista PerCursos, Florianópolis, v. 20, n.43, p. 271 - 294, maio/ago. 2019. 


\title{
Rural education in higher education: the case of the Universidade Federal da Fronteira Sul - Campus Laranjeiras do Sul
}

\begin{abstract}
This work presents some experiences developed in the Rural Education Interdisciplinary Course at Universidade Federal da Fronteira Sul - Campus Laranjeiras do Sul, Paraná, Brazil. The course is a result of the public policies set in order to make public higher education broader in Brazil, as well as take it to Brazilian countryside areas, in the early 21st Century. The research was carried out with the theoretical review of the rural education regulatory frameworks in Brazil, interviews with students, participant observation and access to academic record data provided by the course office and the academic registration office. The result reveals the access, endurance and completion of higher education to people who, historically, had their right to education denied in Brazil, such as indigenous people and peasants. It was verified, also, the new added knowledge, the apprenticeship revealed by the students and the importance of pedagogy of alternation to the completion of the course.
\end{abstract}

Keywords: Rural Education. Pedagogy of alternation. Right to education. 


\section{Introdução}

A Educação do Campo foi estruturada a partir das reivindicações históricas dos camponeses. Abrange os indígenas, os camponeses (incluindo os acampados e assentados do Movimento dos Trabalhadores Rurais Sem Terra - MST), os ribeirinhos, os quilombolas e os faxinalenses. Enfim, todos aqueles que produzem suas condições materiais de existência a partir do trabalho no campo. O propulsor da Educação do Campo, no Brasil, foi o MST, pois nos seus encontros nacionais, na década de 1990, organizou debates, propostas e reivindicações a respeito da luta pela terra e pela educação. Mas de qual educação se tratava? Nessas ocasiões, foi proposta uma educação às pessoas que vivem no campo, que não fosse "urbanocêntrica" (a qual subordina o campo à cidade), mas, sim, voltada aos interesses e à realidade dos que vivem, trabalham e querem continuar no campo.

O objetivo da Educação do Campo é qualificar os espaços educativos, sobretudo os formais, e garantir o acesso, a permanência e a conclusão da escolarização aos camponeses, contribuindo para a permanência dos jovens nesse contexto. As Escolas do Campo se constituem, assim, de espaços nos quais os princípios da Educação do Campo se materializam. Essas escolas são aquelas situadas em área rural ou, ainda, em área urbana, desde que atendam predominantemente as populações do campo. Assim, se há escolas do/no campo, é também necessário pensar na formação dos professores que trabalham nessas escolas. Em suma, a Educação do Campo abrange todos os níveis de formação.

Este texto apresenta e analisa algumas experiências do curso Interdisciplinar em Educação do Campo: Ciências Sociais e Humanas - Licenciatura (IEDOC: CSH), da Universidade Federal da Fronteira Sul - Campus Laranjeiras do Sul - UFFS, no Paraná. O objetivo foi caracterizar o curso citado, analisando como se vincula aos compromissos assumidos pela instituição e ressaltando o seu reflexo na vida dos discentes.

A pesquisa foi elaborada com base em revisão teórica e consulta aos marcos normativos da Educação no Campo no Brasil. Além disso, para a caracterização e análise do curso IEDOC: CSH, foram utilizados dados de registros dos acadêmicos, 
disponibilizados pela secretaria do curso e pela Assessoria de Assuntos Estudantis do Campus Laranjeiras do Sul, referentes aos meses de junho e agosto de 2018. Antes, porém, no segundo semestre de 2017, haviam sido realizadas entrevistas com alguns estudantes do curso para o entendimento do que significa, para eles, estar no ensino superior ${ }^{1}$. Finalmente, considerando o envolvimento dos autores do texto com o objeto aqui tratado, a observação participante também foi uma das técnicas que contribuiu para emoldurar as reflexões apresentadas.

O texto está estruturado, além da introdução e das considerações finais, em três partes principais. Inicialmente tratamos, em linhas gerais, das características da Educação do Campo, ressaltando os seus marcos legais e as políticas públicas sobre o tema; posteriormente, situamos a proposta institucional da UFFS; finalmente, analisamos como esses elementos se materializam no curso Interdisciplinar em Educação do Campo: Ciências Sociais e Humanas - Licenciatura.

\section{O nascedouro da Educação do Campo e seus marcos legais}

No Brasil, com intensa participação popular no período após o golpe militarempresarial de $1964^{2}$ (DREIFUSS, 1987), foi promulgada a Constituição Federal de 1988. Ela é o resultado de uma intensa luta travada entre os movimentos sociais populares e as forças conservadoras. Na Constituição foi instituída uma nova determinação quanto à educação, assegurando o acesso educacional, a permanência e a conclusão da Educação Básica para todos. Consequentemente, isso gerou possibilidades de ingresso no ensino superior também para os povos do campo.

A Constituição Federal estabeleceu o Direito à Educação como Direito Social (art. $6^{\circ}$ ) e determinou (art. 205) que "a educação, direito de todos e dever do Estado e da família, será promovida e incentivada com a colaboração da sociedade, visando ao pleno

\footnotetext{
${ }^{1}$ Com o fim de preservar a identidade dos(as) participantes da pesquisa, trocamos seus nomes reais por "Estudante" mais uma letra do alfabeto diferente para cada entrevistado(a).

${ }^{2}$ Dreifuss (1987) define o golpe militar-empresarial no Brasil em função do fato de que inúmeras empresas aderiram e patrocinaram o Golpe de 1964. Na parte final de sua obra, o autor apresenta farta documentação como prova de que a Coca-Cola, o City Bank, algumas empresas de seguros, entre outras, aportaram dinheiro para que o Golpe militar se concretizasse.
} 
desenvolvimento da pessoa, seu preparo para o exercício da cidadania e sua qualificação para o trabalho" (BRASIL, 1988).

Em 1996, foi publicada a Lei de Diretrizes e Bases da Educação - LDB (Lei n. ${ }^{\circ}$ 9.394/1996), definindo o mundo rural como um espaço específico, diferenciado, mas integrado ao conjunto do país. Essa lei estabelece que os conteúdos e as metodologias devem ser apropriados às reais necessidades e interesses dos estudantes do campo, com a organização escolar e o calendário adequados aos ciclos agrícolas e condições climáticas.

Cinco anos mais tarde, em 2001, teve início uma legislação própria para a Educação do Campo, o Parecer 36/2001, do Conselho Nacional de Educação - CNE, o qual determinou que o campo, "mais do que um perímetro não-urbano, é um campo de possibilidades que dinamizam a ligação dos seres humanos com a própria produção das condições da existência social e com as realizações da sociedade humana" (BRASIL, 2001).

Um ano depois, foram elaboradas as Diretrizes Operacionais para a Educação Básica nas Escolas do Campo (Resolução CNE/CEB n. 01/2002) e, em 2010, foi publicado o Decreto $n^{\circ} 7.352 / 2010$, que dispõe sobre as Políticas de Educação do Campo e o Programa Nacional de Educação na Reforma Agrária - Pronera, o qual propõe e apoia projetos de educação voltados para o desenvolvimento das áreas de reforma agrária. O parágrafo quarto desse Decreto apresenta a amplitude da política:

$\S 4^{\circ}$ A educação do campo concretizar-se-á mediante a oferta de formação inicial e continuada de profissionais da educação, a garantia de condições de infraestrutura e transporte escolar, bem como de materiais e livros didáticos, equipamentos, laboratórios, biblioteca e áreas de lazer e desporto adequados ao projeto político-pedagógico e em conformidade com a realidade local e a diversidade das populações do campo. (BRASIL, 2010, grifo nosso)

A constituição desse arcabouço legal ocorreu diante da ação dos movimentos sociais populares e diferentes organizações que pautaram a necessidade de políticas 
públicas para a Educação do Campo. No que se refere à formação inicial e continuada de professores para as escolas do campo, destaca-se a II Conferência Nacional de Educação do Campo - CNEC, realizada em Luziânia, Goiás, em agosto de 2004, já que "nessa conferência assumiu destaque a formação inicial e continuada dos educadores, assegurada nas universidades públicas de forma gratuita e com o envolvimento dos movimentos sociais" (HAGE; SILVA; BRITO, 2016, p. 151).

Diante dessa conjuntura, foram implantados diferentes programas voltados à formação inicial e continuada de professores para os territórios rurais, como o Pronera, o Programa Escola Ativa, o Programa Projovem Campo Saberes da Terra, o Programa de Apoio à Formação Superior em Licenciatura em Educação no Campo e o Programa de Iniciação à Docência para a Diversidade (HAGE; SILVA; BRITO, 2016). Ainda na mesma esteira, o Ministério da Educação, por meio da Secretaria de Educação Continuada, Alfabetização, Diversidade e Inclusão - SECADI, em 2012, manifestou-se quanto à existência de políticas públicas destinadas à Educação do Campo como uma necessidade “em virtude do reconhecimento da enorme dívida do poder público em relação ao direito dos povos do campo à educação" (SECADI, 2012).

A luta pelo Direito à Educação, em nosso país, é longeva. Pontes de Miranda (1933), quando escreveu Direito à Educação, já manifestava que "onde não se der escola absolutamente gratuita, única, a todos, as massas não devem se enganar: quer-se a continuação das injustiças sociais" (PONTES DE MIRANDA, 1933, p. 25). O autor denunciava, nas conferências em que participava, em 1933, "a existência de indivíduos em idade escolar que, por falta de escola, ou de meios (roupa, transporte), não podem receber instrucção, serve à differenciação social do espírito, correspondente à differença social da actividade physica, a que se chamava escravidão [sic]" (PONTES DE MIRANDA, 1933, p. 11).

A falta de uma política pública educacional para o campo, no Brasil, faz-nos aguçar a memória e relembrar a obra Os Miseráveis, clássico de Victor Hugo, ambientada na França de 1848, uma narrativa da vida da pequena menina Cosette, que vivia no campo e não podia estudar por ser pobre. Naquele país, naquele tempo histórico, eram enormes 
as desigualdades sociais no campo, a ponto de não terem dinheiro para comprar pão quanto mais para ir à escola.

Dessa forma, percebe-se o quão recente é a legislação pertinente à Educação do Campo, visto que foi determinada somente no início do século XXI. Vale ressaltar, contudo, que as ações do Estado voltadas para a educação nas áreas rurais datam das primeiras décadas do século XX, a exemplo da criação, em 1937, da Sociedade Brasileira de Educação Rural (RANGEL; CARMO, 2011; RIBEIRO, 2015). Entretanto,

os vários programas implementados nas décadas de 1930 e 1940 foram prejudicados por fatores que, ainda hoje, interferem nas possibilidades de contribuições efetivas à educação do campo, como o precário conhecimento do contexto de origem dos sujeitos, a pouca participação das escolas nas decisões que regulam o seu funcionamento e a inadequação das políticas às reais demandas do meio rural. (RANGEL; CARMO, 2011, p. 210)

É diante desse histórico que se constitui a luta pela educação dos camponeses, no nível básico e superior, resgatando uma dívida histórica do Estado com os povos do campo. O debate que culmina nas normatizações apresentadas, e que tem impacto na Educação do Campo que conhecemos hoje, teve início na década de 1990. A pressão política e a luta dos sujeitos do campo, juntamente com os seus movimentos e organizações sociais, é que garantiram o reconhecimento e a necessidade de um projeto educacional para o campo. Caldart (2008) assim se manifesta sobre o tema:

A Educação do Campo nasceu como mobilização/pressão de movimentos sociais por uma política educacional para comunidades camponesas: nasceu da combinação das lutas dos sem-terra pela implantação de escolas públicas nas áreas de reforma agrária com as lutas de resistência de inúmeras organizações e comunidades camponesas para não perder suas escolas, suas experiências de educação, suas comunidades, seu território, sua identidade. (CALDART, 2008, p. 71) 
A Educação do Campo se coloca, portanto, contrária ao "campo como lugar de negócio" (CALDART, 2008, p. 71) e, ainda, conforme Caldart (2008), define-se pelas seguintes questões: a consideração da tríade Campo - Política Pública - Educação, tendo como referência a realidade do campo e as políticas públicas para a educação da classe trabalhadora; o reconhecimento das especificidades do campo e dos sujeitos que nele vivem; o movimento da Educação do Campo que, ao mesmo tempo em que denuncia as concepções que consideram o campo como atrasado, também sugere práticas e propostas concretas e projeta "[...] outra concepção de campo, de sociedade, de relação campo e cidade, de educação, de escola. Perspectiva de transformação social e de emancipação humana" (CALDART, 2008, p. 75).

\section{A Educação do Campo e o ensino superior na Universidade Federal da} Fronteira Sul

A UFFS foi instituída pela Lei $\mathrm{n}^{\circ}$ 12.029, de 15 de setembro de 2009, e tem sede no município de Chapecó, Estado de Santa Catarina. Possui, ainda, outros cinco campi nos municípios de Cerro Largo, Erechim e Passo Fundo, no Rio Grande do Sul, e nos municípios de Laranjeiras do Sul e Realeza, no Paraná. A constituição da UFFS reflete o processo de interiorização do ensino superior público no Brasil, em áreas historicamente carentes da oferta dessa modalidade de ensino.

Nessa perspectiva, a UFFS “desenha o seu perfil como universidade multicampi, interestadual, pública, democrática, popular e socialmente comprometida com a realidade sócio-histórica, econômica, política, ambiental e cultural da sua região de inserção" (PLANO DE DESENVOLVIMENTO INSTITUCIONAL, 2012, p. 09). Nos documentos institucionais são recorrentes as referências à realidade das regiões onde os campi estão situados, já que o propósito da universidade é de contribuir diretamente com a melhoria na qualidade de vida da população, sobretudo nos aspectos sociais e econômicos. Os princípios institucionais abordam esses elementos, com destaque para o sexto princípio no qual essa questão aparece de forma explícita: "6. Universidade que estabeleça dispositivos de combate às desigualdades sociais e regionais, incluindo condições de 
acesso e permanência no ensino superior, especialmente da população mais excluída do campo e da cidade" (PLANO DE DESENVOLVIMENTO INSTITUCIONAL, 2012, p. 14).

O Campus Laranjeiras do Sul está situado na mesorregião Centro-Sul do estado do Paraná e oferta sete cursos de graduação e quatro cursos de pós-graduação ${ }^{3}$. Em relação à Educação do Campo, cumpre citar a oferta do curso Interdisciplinar em Educação no Campo: Ciências Naturais, Matemática e Ciências Agrárias - Licenciatura, em regime regular, e o curso Interdisciplinar em Educação no Campo: Ciências Sociais e Humanas Licenciatura, em regime de alternância ${ }^{4}$. Os cursos ofertados no campus revelam o caráter agrário da região e a necessidade de criar alternativas de desenvolvimento que considerem as suas características sociais, econômicas e ambientais.

Essa região se caracteriza por conflitos relacionados à questão agrária, pela marcante presença de movimentos sociais populares - como o MST e o Movimento dos Atingidos por Barragens (MAB) - e pela maior terra indígena do Paraná ${ }^{5}$ a Terra Indígena Rio das Cobras.

Atualmente existem dois acampamentos do MST na região - o Acampamento Herdeiros da Terra de $1^{\circ}$ de Maio, no município de Rio Bonito do Iguaçu, e o Acampamento Dom Tomás Balduíno, em Quedas do Iguaçu. Além deles, há a presença de comunidades quilombolas (nos municípios de Candói, Guarapuava, Palmas, Pinhão, Reserva do Iguaçu e Turvo) e faxinais (no município de Pinhão). Esses elementos representam as diferentes feições do campesinato que continuam resistindo em diferentes movimentos. O Campus Laranjeiras do Sul da UFFS está localizado em uma

\footnotetext{
${ }^{3}$ Os cursos de graduação são: Agronomia - ênfase em Agroecologia; Ciências Econômicas - linha de formação em Desenvolvimento e Cooperativismo; Engenharia de Alimentos; Engenharia de Aquicultura; Interdisciplinar em Educação no Campo: Ciências Sociais e Humanas - Licenciatura; Interdisciplinar em Educação no Campo: Ciências Naturais, Matemática e Ciências Agrárias - Licenciatura; e Pedagogia. Os cursos de pós-graduação Lato Sensu são: Especialização em Economia Empresarial e Gestão de Pequenos Negócios e Especialização em Realidade Brasileira. Os cursos de pós-graduação Stricto Sensu são: Mestrado em Agroecologia e Desenvolvimento Rural Sustentável e Mestrado em Ciência e Tecnologia de Alimentos.

${ }^{4}$ No Campus Erechim também é ofertado o curso Interdisciplinar em Educação do Campo: Ciências da Natureza - Licenciatura.

${ }^{5}$ Terra Indígena (TI) é uma porção do território nacional, de propriedade da União, habitada por um ou mais povos indígenas, por ele(s) utilizada para suas atividades produtivas, imprescindível à preservação dos recursos ambientais necessários a seu bem-estar e necessária à sua reprodução física e cultural, segundo seus usos, costumes e tradições. Trata-se de um tipo específico de posse, de natureza originária e coletiva, que não se confunde com o conceito civilista de propriedade privada (FUNAI, 2019).
} 
área de assentamento da reforma agrária, o que revela a importância dos movimentos sociais populares no processo de criação da universidade.

\section{O curso Interdisciplinar em Educação do Campo: Ciências Sociais e Humanas - Licenciatura (IEDOC: CSH) e o perfil dos estudantes}

O curso IEDOC: CSH é resultado de uma política pública direcionada à criação de cursos superiores de licenciatura em Educação do Campo, estabelecida pelo Edital $n^{\circ}$ 02/2012 da SECADI/MEC. Esse edital aprovou 42 projetos de cursos em diferentes instituições de ensino superior, disponibilizando 600 vagas de docentes e 126 técnicos permanentes nas instituições cujos projetos foram aprovados. Os cursos de Licenciatura em Educação do Campo são ofertados por área do conhecimento, com o objetivo de habilitar profissionais para atuarem nos anos finais do ensino fundamental, ensino médio e em processos educativos comunitários (MOLINA; HAGE, 2016).

O curso IEDOC: CSH habilita para atuação nas disciplinas de Geografia, História, Sociologia e Filosofia, preferencialmente nas escolas do campo. O ingresso no curso é realizado por meio de processo seletivo especial. Essa forma de ingresso se caracteriza pelo envolvimento direto dos docentes e técnicos do curso com o processo de elaboração do edital e da prova de seleção, divulgação e correção das provas. O processo seletivo especial garante que o público-alvo do curso tome conhecimento da sua existência e gere mecanismos de aproximação da universidade com a comunidade regional.

O curso possui 132 estudantes com matrícula ativa, sendo que 09 estudantes estão no último semestre. Os estudantes estão distribuídos, atualmente, em 04 turmas. A formatura da primeira turma do curso, com 19 estudantes, ocorreu em fevereiro de 2018. A apresentação do perfil do curso toma como base o número total de estudantes com matrícula ativa e aqueles já formados, totalizando 151 acadêmicos ${ }^{6}$. Os dados são do mês de junho de 2018.

\footnotetext{
${ }^{6}$ As turmas ingressaram no curso nos seguintes anos e semestres: 2013/02; 2014/01; 2015/01; 2015/02; 2016/02 e 2017/01.
} 
O curso segue a tendência das licenciaturas de possuir maior número de estudantes do sexo feminino. No total, são 91 do sexo feminino e 60 do sexo masculino, respectivamente $60 \%$ e $40 \%$. A média de idade dos estudantes é de 24,2 anos. A maior parte dos estudantes possui idade entre 21 e 25 anos, como apresentado no gráfico a seguir.

Figura 01 - Idade dos estudantes do curso IEDOC: CSH

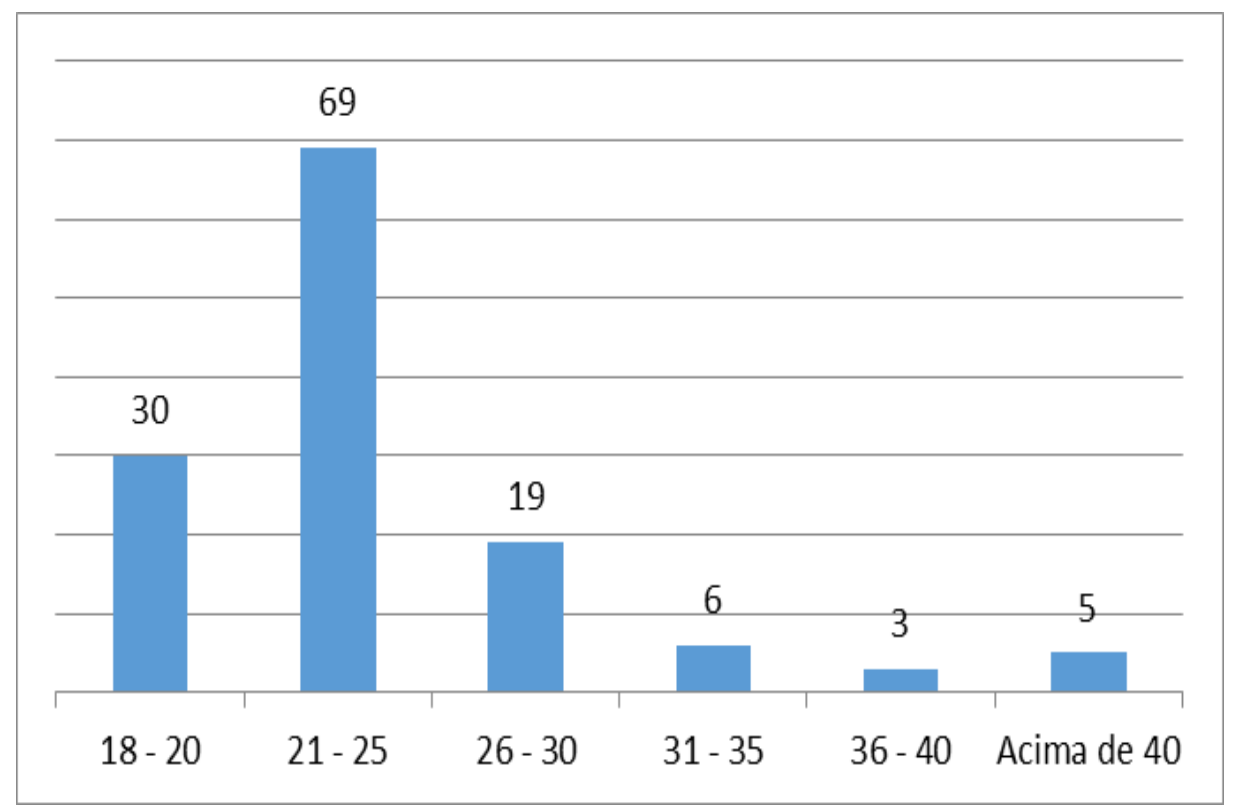

Fonte: Elaborado pelos autores, 2018.

Em relação ao grupo étnico dos estudantes do curso, destacam-se os pardos, com 59 estudantes (39\%), e os indígenas, com 46 estudantes (30\%) (Figura 02). Os indígenas são oriundos de três diferentes Terras Indígenas do Paraná: Terra Indígena Marrecas, localizada nos municípios de Guarapuava e Turvo; Terra Indígena Rio das Cobras, dos municípios de Espigão Alto do Iguaçu e Nova Laranjeiras; e Terra Indígena Mangueirinha, situada nos municípios de Chopinzinho, Coronel Vivida e Mangueirinha. 
Figura 02 - Autodeclaração étnico-racial dos estudantes do curso IEDOC: CSH

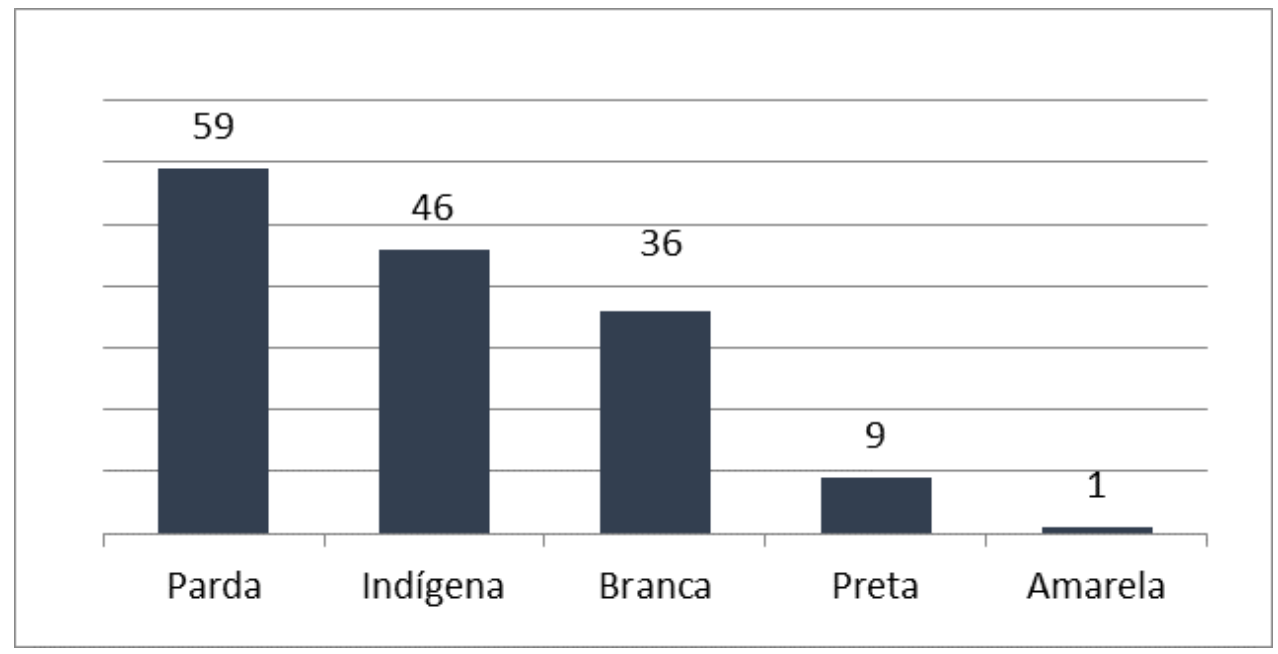

Fonte: Elaborado pelos autores, 2018.

O número expressivo de indígenas no curso, de acordo com Manduca (2017), é resultado de basicamente três fatores: a identificação com a proposta do curso, a proximidade do local de oferta do curso com a terra indígena onde os estudantes residem e o fato de o curso ser oferecido em sistema de alternância - tema abordado na próxima seção. No total, nos cursos de graduação do Campus Laranjeiras do Sul estão matriculados 50 estudantes indígenas, sendo que 46 pertencem ao curso IEDOC: CSH.

Os indígenas, com frequência, manifestam o interesse em contribuir com a terra onde residem. Sobre essa questão, um dos estudantes, que é indígena kaingang, explicou que "o curso é muito importante, porque trouxe novos conhecimentos na minha vida, para que depois que eu concluir possa atuar na aldeia e transmitir os conhecimentos para os alunos da escola" (Estudante A, 2017). Outra estudante indígena reforça esse mesmo entendimento ao afirmar: "a Educação no Campo é importante na minha vida pelo fato de adquirir mais conhecimento e compartilhar esse conhecimento na minha comunidade, na minha aldeia" (Estudante B, 2017). Uma terceira estudante indígena apresenta o seguinte entendimento sobre o curso:

estar no ensino superior público foi conseguir superar um pouco minhas dificuldades. Esse curso proporcionou um conhecimento mais amplo [...]. 
Aprendi a ser crítica e evoluiu o modo de eu me expressar em português. Isso é importante para ajudar a minha comunidade. Mas, quero buscar mais conhecimento, não só trabalhar na aldeia, depois que eu concluir o curso, estou disposta a ir além, porque assim fica mais fácil realizar algo importante para o meu povo Kaingang da Terra Indígena de Rio das Cobras, no município de Nova Laranjeiras, no Paraná. (Estudante C, 2017)

Apenas três estudantes do curso não residem no estado do Paraná, e sim em Santa Catarina. Entre aqueles que residem no Paraná, 84 estudantes ( $56 \%$ do total) moram em municípios da região Centro-Sul do estado, mesma região onde está situado o Campus Laranjeiras do Sul da UFFS. Esse dado revela que o curso IEDOC: CSH contribui diretamente para a qualificação profissional na região em que a universidade se encontra instalada e cumpre, portanto, com o proposto no Plano de Desenvolvimento Institucional - PDI, citado em passagem anterior. Apesar de morar distante da universidade, uma estudante explicou que: “logo no início encontrei algumas dificuldades para vir até Laranjeiras do Sul estudar, motivo este de morar longe, aproximadamente $300 \mathrm{~km}$. Mas, apesar de todas as limitações, o meu sonho de ser professora falou mais alto" (Estudante D, 2017).

Como a maior parte dos estudantes possui idade entre 18 e 25 anos (Figura 01), a maioria deles também concluiu o ensino médio depois de 2010 (Figura 03). Esse dado revela que os estudantes do curso não deixaram de estudar por um período significativo após a conclusão do ensino básico para ingressar na universidade.

Figura 03 - Ano de conclusão do Ensino Médio dos estudantes do curso IEDOC: CSH

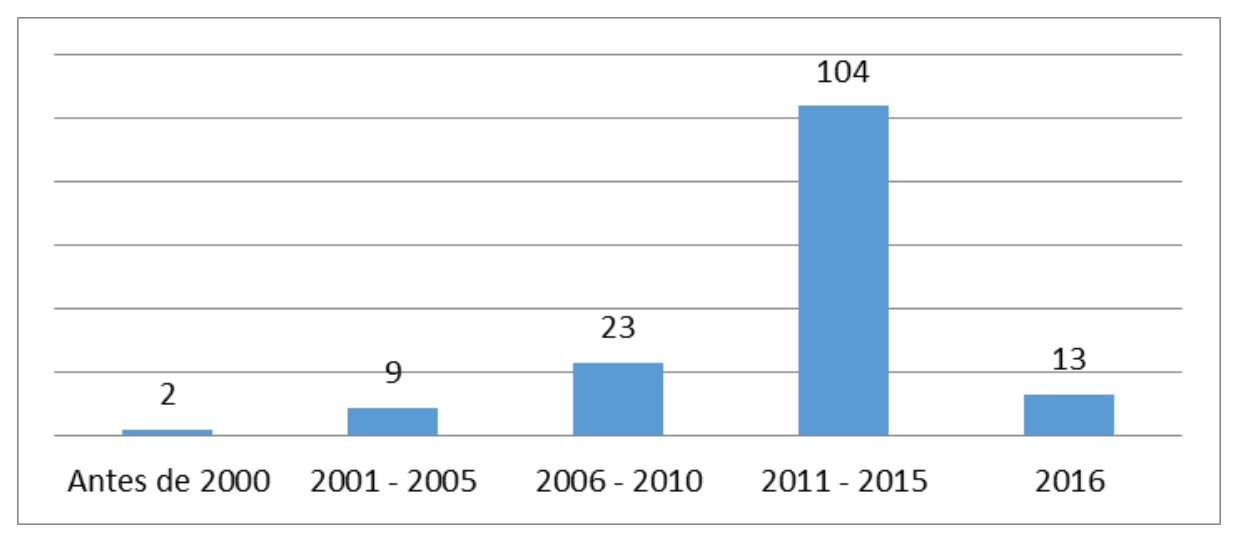

Fonte: Elaborado pelos autores, 2018. 
Outro índice importante é aquele relacionado aos auxílios socioeconômicos

recebidos pelos estudantes do curso. Os auxílios socioeconômicos da instituição abrangem o transporte, alimentação, moradia e o auxílio estudantil. Como os estudantes possuem os custos de hospedagem e alimentação arcados com recursos dos editais de abertura do curso e/ou outros recursos públicos, eles podem acessar o auxílio estudantil e o auxílio transporte.

O edital do processo seletivo para auxílios socioeconômicos da UFFS, do ano de 2018, dispõe que o auxílio estudantil pode ser, por mês, de vinte ( $R \$ 20,00)$, cinquenta e cinco ( $R \$ 55,00)$ ou cento e trinta reais ( $R \$ 1$ 130,00), dependendo do Índice de Vulnerabilidade Socioeconômica ${ }^{7}$ - IVS do estudante. Entre os discentes do curso, 54 estão recebendo auxílios socioeconômicos. Esses estudantes recebem recurso por apresentarem situação de vulnerabilidade social avaliada em análise socioeconômica. Entre aqueles que recebem o auxílio, 43 estudantes vêm de grupos familiares com IVS de até 400 (com renda de aproximadamente meio salário mínimo por pessoa da família), um estudante apresenta IVS de até 800 e um estudante possui IVS de até 1.320. Além disso, os 46 estudantes indígenas recebem Bolsa Permanência, independente da renda familiar, no valor de novecentos reais $(R \$ 900,00)$.

Os dados apresentam que mais de $70 \%$ dos estudantes recebem algum tipo de auxílio. Vale destacar que o fato de o curso ser ofertado em regime de alternância

\footnotetext{
7 De acordo com o Art. 10 da Resolução n 10/2016 - CONSUNI/CGAE, "Para o cálculo do índice de Vulnerabilidade Socioeconômica (IVS) do estudante serão considerados os seguintes fatores: I - renda familiar bruta mensal (com os descontos previstos e descritos nesta Resolução); II - número de membros do grupo familiar, incluindo o estudante; III - despesas com moradia do estudante e dos pais ou responsáveis; IV - despesas do estudante com transporte para suas atividades acadêmicas; $V$ - doença crônica e/ou deficiência no grupo familiar; VI - bens patrimoniais do grupo familiar; VII - condições favoráveis e/ou agravantes definidos pelo Serviço Social da UFFS" (CONSUNI, 2016, p. 05). Os valores de cada auxílio variam de acordo com a faixa de IVS do estudante, podendo ser: Faixa I (IVS até 400); Faixa II (IVS de 401 até 800 ); Faixa III (IVS de 801 até 1.320).
} 
também é fundamental para a inserção dos estudantes de baixa renda, já que os custos dos estudantes se restringem ao material didático e ao transporte até o local das aulas.

\subsection{A Educação do Campo e a Pedagogia da Alternância}

A Pedagogia da alternância teve início na década de 1930, na França. Ela foi utilizada como alternativa metodológica de formação profissional agrícola para filhos de agricultores que procuraram uma solução junto ao padre da aldeia, Abbé Granereau, tendo em vista o desinteresse dos jovens em frequentar a escola. A alternância ocorria por meio de um período de estudos na escola e outro nas propriedades agrícolas de residência dos estudantes. Com base em diferentes autores, Teixeira et al. (2008) afirmam que a ideia básica era conciliar o estudo na escola com o trabalho na propriedade, assim, "no tempo na escola, o ensino era coordenado por um técnico agrícola; no tempo na família, os pais se responsabilizavam pelo acompanhamento das atividades dos filhos" (TEIXEIRA et al., 2008, p. 229).

No Brasil, a Pedagogia da Alternância foi implementada em 1969, no Espírito Santo, por meio da ação do Movimento de Educação Promocional que resultou na criação de diferentes escolas rurais (BRASIL, 2006). O Parecer CNE/CEB $n^{\circ}$. 1/2006 deixa claro que a Pedagogia da Alternância

[...] vem se mostrando como a melhor alternativa para a Educação Básica, neste contexto, para os anos finais do Ensino Fundamental, o Ensino Médio e a Educação Profissional Técnica de nível médio, estabelecendo relação expressiva entre as três agências educativas família, comunidade e escola. (BRASIL, 2006)

Esse método, em que se alternam situações de aprendizagem escolar com situações de trabalho produtivo, exige formação específica para os professores. Bicalho (2013) destaca que a pedagogia da alternância propõe gestão participativa, estabelecendo relações cotidianas e democráticas entre a escola e a comunidade, as quais saem fortalecidas nas ações coletivas e sociais. Assim, educadores e educandos 
produzem conhecimentos quando ensinam e aprendem em uma relação dialógica. Ribeiro (2008) reforça esse mesmo entendimento ao afirmar que "a Pedagogia da Alternância também articula prática e teoria numa práxis e realiza-se em tempos e espaços que se alternam entre escola e propriedade, comunidade, assentamento, acampamento ou movimento social ao qual o educando está vinculado" (RIBEIRO, 2008, p. 30).

Pode-se afirmar, com base nesse entendimento, que a alternância aproxima e articula pedagogicamente a escola com a comunidade de origem dos seus estudantes. De acordo com Ribeiro (2008),

[...] a Pedagogia da Alternância é uma expressão polissêmica que guarda elementos comuns, mas que se concretiza de diferentes formas: conforme os sujeitos que as assumem, as regiões onde acontecem as experiências, as condições que permitem ou limitam e até impedem a sua realização e as concepções teóricas que alicerçam suas práticas. Com esse cuidado e de modo amplo, pode-se dizer que a Pedagogia da Alternância tem o trabalho produtivo como princípio de uma formação humanista que articula dialeticamente ensino formal e trabalho produtivo. (RIBEIRO, 2008, p. 30)

O IEDOC: CSH se organiza com base na pedagogia da alternância. Isso significa que o curso estrutura o semestre letivo em três etapas: duas etapas de Tempo Universidade (TU) intercaladas por um período de Tempo Comunidade (TC). O TU tem duração de 20 a 25 dias consecutivos de aulas e o TC tem duração de aproximadamente um mês. Durante o TC os estudantes retornam para as comunidades onde residem e realizam parte das atividades e da carga horária dos componentes curriculares, inclusive os estágios curriculares nas escolas. Essa proposta assim se apresenta no Projeto Pedagógico do Curso - PPC:

[...] a alternância permitirá maior ligação com a realidade social e institucional do campo. Para os estudantes, a vivência dos processos educativos de forma alternada permite que ele parta das experiências de formação na família, na comunidade local, na instituição, no município em que vive e na escola onde realizará a PCC [Prática como Componente 
Curricular] e estágios. Trata-se, de fato, de uma perspectiva de práxis, ao relacionar os saberes produzidos no campo com os saberes científicos. Por isso, a alternância adotada na Licenciatura estimula, como elementos fundamentais de formação, o exercício da pesquisa e a articulação entre trabalho e estudo.

A relação entre o Tempo Universidade e o Tempo Comunidade será pedagogicamente pensada, de forma que o estudo e as reflexões, ao mesmo tempo gerem novidades no campo conceitual e operativo das práticas sociais e, na relação oposta, a vivência nas práticas políticas, sociais, culturais e produtivas gerem problemas, questões, tensões, que serão reaproveitadas pelo processo escolar, demandando novas incursões pelo conhecimento sistematizado. (PROJETO PEDAGÓGICO DO CURSO, 2013, p. 43)

Portanto, na materialização da proposta da alternância no curso devem ser destacados dois aspectos: o pedagógico e o organizacional.

No aspecto pedagógico, a alternância possibilita aproximar a realidade vivida pelo estudante com as questões teóricas estudadas pelas ciências sociais e humanas articuladas ao estudo para a formação de professores. Essa aproximação exige planejamento das aulas e das atividades integradoras (seminários, estudo de textos, pesquisa de campo, entre outras) e é parte do desafio enfrentado pelo corpo docente do curso. Durante as entrevistas, uma das estudantes menciona essa questão. Segundo ela, o curso proporcionou "a superação de limites, novos conhecimentos e aprendizados, consegui estabelecer uma relação entre teoria e prática tornando-me um sujeito mais crítico e pensante em nossa sociedade, valorizando o sujeito e sua relação com o meio em que está inserido" (Estudante D, 2017).

No aspecto organizacional, a alternância amplia o acesso ao ensino superior e facilita a permanência dos estudantes que ingressam no curso. Esses discentes certamente não poderiam realizá-lo se fosse ofertado em regime regular, ou seja, com aulas diárias durante todo o semestre na universidade. A distância dos seus locais de residência em relação à universidade, os custos com o deslocamento e o aluguel e, principalmente, a necessidade de estar presente na unidade de produção para a realização do trabalho inviabilizariam a realização do curso. Uma das estudantes destaca essa questão ao afirmar: "o modelo de alternância possibilitou a minha permanência na 
Universidade Federal da Fronteira Sul, tanto que este ano finalizamos o curso, visto sermos a primeira turma que iniciou no segundo semestre de 2013" (Estudante D, 2017).

A pedagogia da alternância gera autonomia, fortalecimento da autoestima, responsabilidade e compromisso dos estudantes com o seu conhecimento e aperfeiçoamento metodológico. Com Gramsci (2000), a Educação do Campo reitera a necessidade de que

todo grupo social, nascendo no terreno originário de uma função essencial no mundo da produção econômica, cria para si, ao mesmo tempo, organicamente, uma ou mais camadas de intelectuais que lhe dão homogeneidade e consciência da própria função, não apenas no campo econômico, mas também no social e no político. (GRAMSCl, 2000, p. 15)

Desse modo, o curso de IEDOC: CSH procura vivenciar os ensinamentos de Gramsci (2000), no sentido de incentivar a participação ativa dos estudantes na escola, pois essa somente pode existir se a escola for ligada à vida. Isso fortalece a formação de intelectuais orgânicos da classe trabalhadora.

Outro elemento do curso relacionado com a pedagogia da alternância é o trabalho produtivo, como apontado anteriormente por Ribeiro (2008). A maior parte das aulas do curso ocorre no Centro de Desenvolvimento Sustentável e Capacitação em Agroecologia - Unidade Vila Velha - Ceagro, localizado no município de Rio Bonito do Iguaçu, distante cerca de 30 quilômetros do Campus Laranjeiras do Sul. As aulas no campus ocorrem uma vez por semana durante o Tempo Universidade. O Ceagro possui estrutura física com salas de aula, alojamento, biblioteca, refeitório e cozinha, o que permite aos estudantes permanecerem naquele espaço durante o período das aulas. Entretanto, para garantir a oferta dos serviços necessários ao desenvolvimento do curso, os estudantes contribuem com a limpeza e organização dos espaços de uso comum e dos utensílios utilizados para as refeições. Essas tarefas exigem a realização do trabalho em equipe, com divisão de tarefas, e geram responsabilidade com o coletivo. 
Aliado à formação dos estudantes, mais um ponto importante é a existência, no espaço do Ceagro, da ciranda para as crianças, uma espécie de creche para os(as) filhos(as) de até 06 anos de idade das estudantes que frequentam o curso. Isso garante que as estudantes mães possam frequentar o ensino superior sem se distanciar dos filhos pequenos. No depoimento de uma delas, verifica-se a importância da ciranda infantil:

a dinâmica do curso organizado em alternância é o método que viabiliza e assegura nossa permanência na instituição. Para além dessa pedagogia permite - nós que somos mães - trazer nossos filhos e ao mesmo tempo estudar, ou seja, a ciranda é um elemento fundamental na alternância. (Estudante E, 2017)

Finalmente, cabe citar o convívio entre indígenas, camponeses (acampados e assentados da reforma agrária, quilombolas e aqueles(as) oriundos(as) de diferentes comunidades rurais) com estudantes da área urbana de pequenos municípios do Estado do Paraná. As cinco primeiras turmas do curso contam com um total de 18 estudantes residentes em acampamentos e 30 em assentamentos da reforma agrária, além de um quilombola. Uma estudante indígena assim se refere ao MST: “eu não fazia a mínima ideia sobre esse movimento social e nem do Movimento dos Pequenos Agricultores - MPA. Mas esse curso me fez compreender sobre tudo isso" (Estudante F, 2017). Outro estudante ressalta a importância do curso nos seguintes termos:

sou de origem camponesa, mais especificamente de área de assentamento de Reforma Agrária. Vivenciei uma realidade marcada pelo preconceito contra os Povos do Campo. Neste sentido, a formação de professores que valorizam e interpretem essa realidade se faz necessária. (Estudante G, 2017)

Torna-se possível, assim, demonstrar que a Educação do Campo e a pedagogia da alternância trazem mudanças benfazejas no ensino superior para os povos do campo, com possibilidades e condições para que estudem, mesmo vivendo em condições de vulnerabilidade socioeconômica. Ao ser questionada sobre o significado de estar 
concluindo a graduação em uma universidade federal, uma estudante indígena Kaingang afirma:

Hoje em dia a menina que era tímida na escola, desde as séries iniciais ao Ensino Médio, levanta críticas. Posso dizer que ensinar os indígenas também foi um desafio grande para os educadores do curso, mas eles foram persistentes dentro da sala de aula, pelas conversas que tínhamos com os professores, a relação foi sendo mais de confiança e assim foram sendo encontrados novos métodos para os conteúdos. (Estudante $\mathrm{H}$, 2017)

O depoimento de um estudante assentado do MST revela que esse é um modelo de educação que valoriza os camponeses, a quem foi negado o direito à escolarização, desde os primórdios: "O curso me proporcionou um olhar pedagógico diferenciado em relação à vida no campo, podendo assim contribuir com meu assentamento, sabendo que esse curso é resultado da luta dos movimentos sociais" (Estudante I, 2017).

\section{Considerações finais}

Este trabalho registrou algumas das práticas da Educação do Campo, de ensino superior, no Curso Interdisciplinar em Educação do Campo: Ciências Sociais e Humanas Licenciatura, da Universidade Federal Fronteira Sul - Campus Laranjeiras do Sul, no Paraná, e seu significado na vida dos estudantes indígenas (Kaingang e Guarani), acampados(as), assentados(as) do MST e filhos(as) de pequenos agricultores.

O discurso dos estudantes entrevistados foi a voz da esperança, de novas possibilidades na vida. Isso vai ao encontro do posicionamento de Milton Santos (1997), geógrafo brasileiro, para quem o discurso da desesperança é o discurso do opressor. Cabe aos novos educadores do campo levar e implementar o discurso da esperança em um novo campo de possibilidades.

O curso IEDOC: CSH está cumprindo com o objetivo de sua criação ao se constituir como instrumento para a inserção, a permanência e a conclusão do ensino superior público à população que, historicamente, não teve acesso a essa modalidade de ensino 
no Brasil. Essa meta só se concretizou pela articulação de diferentes políticas públicas que culminaram na criação de universidades e de cursos com características específicas, como a organização curricular em regime de alternância. Ademais, a presença de estudantes oriundos da região onde está localizado o Campus Laranjeiras do Sul e as características socioeconômicas das famílias dos estudantes revelam que o curso está fortemente alinhado aos princípios institucionais da UFFS.

Dificuldades existem, mas elas foram ou ainda podem ser superadas. O Brasil escravista que negou o Direito à Educação de nível superior para os indígenas, camponeses, quilombolas, ribeirinhos, filhos de pequenos agricultores e faxinalenses vem sendo superado nessa experiência - mas ainda há um longo percurso a ser percorrido.

\section{Referências}

BICALHO, Ramofly. Educação do campo e pedagogia da alternância no Brasil. Educere Et Educare, Cascavel: Unioeste, v. 8, n. 15, p. 45-58, jan./jun. 2013.

\section{BRASIL. [Constituição (1988)]. Constituição da República Federativa do Brasil de 1988.} Brasília, DF: Presidência da República, [2018]. Disponível em: https://www.senado.gov.br/atividade/const/con1988/CON1988_05.10.1988/art_205_.asp. Acesso em: 19 set. 2018.

BRASIL. Ministério da Educação. Conselho Nacional de Educação. Parecer n. ${ }^{\circ}$ 36/2001 do Conselho Nacional de Educação. [Brasília, DF]: Ministério da Educação, 2001. Disponível em:http://pronacampo.mec.gov.br/images/pdf/mn_parecer_36_de_04_de_dezembro_de _2001.pdf. Acesso em: 12 nov. 2017.

BRASIL. Ministério da Educação. Conselho Nacional de Educação. Parecer CNE/CEB n ${ }^{\circ}$ : 1/2006. [Brasília, DF]: Ministério da Educação, 2006. Disponível em: http://portal.mec.gov.br/cne/arquivos/pdf/pcebo01_06.pdf. Acesso em: 31 ago. 2018.

BRASIL. Decreto $\mathbf{n}^{\circ} \mathbf{7 \cdot 3 5 2}$, de 4 de novembro de 2010. Dispõe sobre a política de educação do campo e o Programa Nacional de Educação na Reforma Agrária - PRONERA. [Brasília, DF: s.n.], 2010. Disponível em: http://www.planalto.gov.br/ccivil_03/_at020072010/2010/decreto/d7352.htm. Acesso em: 20 ago. 2018. 
CALDART, Roseli Salete. Sobre a educação do campo. In. SANTOS, C. A. (Org.). Por uma educação do campo: campo - políticas públicas - educação. Brasília: Incra/MDA, 2008. p.67-86.

CONSELHO UNIVERSITÁRIO - CONSUNI. Resolução n 10/2016 - Consuni/CGAE. Estabelece regras para a realização de análise socioeconômica e habilitação para inscrição nos auxílios socioeconômicos. Chapecó: Conselho Universitário, 2016. Disponível em: https://www.uffs.edu.br/atos-normativos/resolucao/consunicgae/2016-0010. Acesso em: 19 set. 2018.

DREIFUSS, René Armand. 1964: a conquista do Estado - ação política, poder e golpe de classe. Petrópolis, RJ: Vozes, 1987.

ESTUDANTE A. [Entrevista cedida a] Maria Eloá Gehlen, Rio Bonito do Iguaçu (PR), 23 nov. 2017.

ESTUDANTE B. [Entrevista cedida a] Maria Eloá Gehlen, Rio Bonito do Iguaçu (PR), 23 nov. 2017.

ESTUDANTE C. [Entrevista cedida a] Maria Eloá Gehlen, Rio Bonito do Iguaçu (PR), 24 nov. 2017.

ESTUDANTE D. [Entrevista cedida a] Maria Eloá Gehlen, Rio Bonito do Iguaçu (PR), 24 nov. 2017.

ESTUDANTE E. [Entrevista cedida a] Maria Eloá Gehlen, Rio Bonito do Iguaçu (PR), 24 nov. 2017.

ESTUDANTE F. [Entrevista cedida a] Maria Eloá Gehlen, Rio Bonito do Iguaçu (PR), 05 dez. 2017.

ESTUDANTE G. [Entrevista cedida a] Maria Eloá Gehlen, Rio Bonito do Iguaçu (PR), 05 dez. 2017.

ESTUDANTE H. [Entrevista cedida a] Maria Eloá Gehlen, Rio Bonito do Iguaçu (PR), 07 dez. 2017.

ESTUDANTE I. [Entrevista cedida a] Maria Eloá Gehlen, Rio Bonito do Iguaçu (PR), 07 dez. 2017.

FUNAI - FUNDAÇÃO NACIONAL DO ÍNDIO. Terras Indígenas: o que é? Brasília, DF: FUNAI. Disponível em: http://www.funai.gov.br/index.php/nossas-acoes/demarcacao-de-terrasindigenas. Acesso em: 07 jan. 2019. 
GRAMSCI, Antônio. Cadernos do Cárcere. Volume 2. Rio de Janeiro: Civilização Brasileira, 2000.

HAGE, Salomão Antônio Mufarrej; SILVA, Hellen do Socorro de Araújo; BRITO, Márcia Mariana Bitencourt. Educação superior do campo: desafios para a consolidação da licenciatura em educação do campo. Educação em Revista, Belo Horizonte, v.32, n.04, p. 147-174, 2016.

HUGO, Victor. Os Miseráveis. Sumaré, SP: Martin Claret, 2014.

MANDUCA, Adelar Fagpri Felix Nunes. Da aldeia à universidade: os acadêmicos indígenas no curso Interdisciplinar em Educação do Campo: Ciências Sociais e Humanas Licenciatura da Universidade Federal da Fronteira Sul. 2017. Trabalho de Conclusão de Curso (Interdisciplinar em Educação do Campo: Ciências Sociais e Humanas - Licenciatura) - Universidade Federal da Fronteira Sul, Laranjeiras do Sul, PR, 2017.

MOLINA, Mônica Castagna; HAGE, Salomão Mufarrej. Riscos e potencialidades na expansão dos cursos de licenciatura em Educação do Campo. RBPAE, Porto Alegre, v. 32, n. 3, p. 805 - 828 set./dez. 2016.

PLANO DE DESENVOLVIMENTO INSTITUCIONAL - PDI. 2012-2018. Universidade Federal da Fronteira Sul (UFFS). Chapecó/SC: [s.n.], 2012. Disponível em: https://www.uffs.edu.br/ institucional/a_uffs/a_instituicao/plano_de_desenvolvimento_institucional. Acesso em: 12 jun. 2018.

PONTES DE MIRANDA, Francisco Cavalcanti. O Direito à Educação. Rio de Janeiro: Editora Alba Limitada, 1933.

PROJETO PEDAGÓGICO DO CURSO - PPC. Curso Interdisciplinar em Educação do Campo: Ciências Sociais e Humanas - Licenciatura. Laranjeiras do Sul, PR: [s.n.], 2013. Disponível em: https://www.uffs.edu.br/campi/laranjeiras-do-sul/cursos/. Acesso em: 02 jul. 2018.

RANGEL, Mary; CARMO, Rosângela Branca. Da educação rural à educação do campo: revisão crítica. Revista da FAEEBA - Educação e Contemporaneidade, Salvador, v. 20, n. 36, p. 205-214, jul./dez. 2011.

RIBEIRO, Marlene. Pedagogia da alternância na educação rural/do campo: projetos em disputa. Educação e Pesquisa, São Paulo, v.34, n.1, p. 027-045, jan./abr. 2008.

RIBEIRO, Marlene. Reforma agrária, trabalho agrícola e educação rural: desvelando conexões históricas da educação do campo. Educação e Pesquisa, São Paulo, v. 41, n. 1, p. 79-100, jan./mar. 2015. 
SANTOS, Milton. Milton Santos - Um militante da esperança. [Entrevista cedida a] Karla Hansen. Educação Pública, Rio de Janeiro, dezembro de 1997. Disponível em: http://www.educacaopublica.rj.gov.br/biblioteca/geografia/0023.html. Acesso em: 09 jul. 2018.

SECADI. Secretaria de Educação Continuada, Alfabetização, Diversidade e Inclusão. Educação do Campo: marcos Normativos. Brasília: SECADI, 2012.

TEIXEIRA, Edival Sebastião; BERNARTT, Maria de Lourdes; TRINDADE, Glademir Alves. Estudos sobre Pedagogia da Alternância no Brasil: revisão de literatura e perspectivas para a pesquisa. Educação e Pesquisa, São Paulo, v.34, n.2, p. 227-242, maio/ago. 2008. 